\title{
Chromatographic study of the recovered gases from hydropyrolytic de-polymerization of LDPE, MDPE and HDPE mix type of waste polyethylene
}

\author{
Gautam Kumar Roy ${ }^{1} \cdot$ Bipin Kumar ${ }^{2} \cdot$ Swatantreshwar Jha $^{3}$
}

Received: 2 May 2015/ Accepted: 23 September 2015/Published online: 18 November 2015

(C) The Author(s) 2015. This article is published with open access at Springerlink.com

\begin{abstract}
The thirst of energy is one of the biggest challenges the world is facing today. The search for new alternative and renewable source of energy is being studied worldwide. The emission of harmful gases such as $\mathrm{NO}_{x}$, $\mathrm{SO}_{x}, \mathrm{CO}$ and $\mathrm{CO}_{2}$ and other greenhouse gases in the environment contributes to the global warming and also causes health related problems. Polyethylenes are substances which take longer time for its decomposition and are one of the biggest threats to the environment. The waste polyethylene was thermally de-polymerized and during such process the gases recovered were studied. The study was carried out on low-medium and high-density polyethylene mix. The study of the waste polyethylene into useful hydrocarbon products provides scope for further investigation on this field for the production of domestic fuel. The comparisons of the recovered gases with the LPG gas components were also studied and there fuel property is discussed. This paper describes the gaseous hydrocarbon components recovered during the process of thermal degradation of polyethylene. The component recovered and their importance as fuel is also studied.
\end{abstract}

Keywords Polyethylene - De-polymerization . Hydrocarbon · Fuel gas · Gas chromatograph

Gautam Kumar Roy

gautam_roy81@yahoo.co.in

1 University Department of Chemistry, Lalit Narayan Mithila University, Darbhanga, India

2 G. D. College (Unit of Lalit Narayan Mithila University, Darbhanga), Begusarai, India

3 University Department of Chemistry, Lalit Narayan Mithila University, Darbhanga, India

\section{Introduction}

Solid waste management continues to evolve and much of the evolution is driven by the adoption of new technologies that increases the recovery capacity and processing capacity [1]. Waste polyethylenes, basically LDPE, MDPE and HDPE type of polyethylenes represents a large amount of municipal waste every year. Polyethylenes are the nonbiodegradable materials which are generally made up of a large number of organic resins. Poly bags, plastic toys etc. are generally made up of these types of organic resins, these materials are generally low density polyethylenes (LDPE), medium density polyethylenes (MDPE) and high density polyethylenes (HDPE). Land filling of polyethylene could result in plastic additives such as phthalates and various dyes polluting ground water. Incineration is an alternative to landfill disposal of plastic wastes, but this practice could result in the formation of unacceptable emission of gases such as nitrous oxide, sulfur oxide, dusts [2]. Polymers made up of long chain carbon atoms and hydrogen atoms $(-\mathrm{CH}-)$ n along with some traces of oxygen, sulfur and nitrogen. These are generally chain linking in which large number of repeated units of monomers is binds together.

$\mathrm{nCH} 2=\mathrm{CH} 2 \rightarrow[-\mathrm{CH} 2-\mathrm{CH} 2-]-\mathrm{n}-$

Polyethylene, generally have very strong chemical bond that make it durable and resistant to natural activity. Polyethylene to hydrocarbon fuel is a de-polymerization process of converting waste polyethylene into useful hydrocarbon products. The process of converting the polyethylene into useful hydrocarbon product is followed by hydropyrolytic process. The thermo chemical decomposition of organic material at elevated temperature in the absence of oxygen is studied in this paper. The chromatographic study of the gaseous

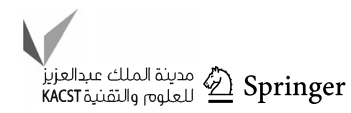


products obtained were studied, there properties and use as a domestic fuel is also studied in this paper. The gaseous hydrocarbon product obtained in this process range from $\mathrm{C} 1$ to $\mathrm{C} 4$ with some $\mathrm{C} 5$ and C6 components. Unlike mechanical recycling technique, in which the long polymeric chains of the plastic are preserved intact, pyrolysis produces lower molecular weight components. The formation of carbonized char and a volatile fraction that can be separated into condensable hydrocarbon oil and a non-condensable high calorific value gas. The proportion of each fraction and there precise composition depends primarily on the nature of the plastic waste, but also on process condition [3]. The Gas chromatography study of the gaseous product reflects the usefulness of the gaseous hydrocarbon product as an alternative fuel.

\section{Methodology}

The waste polyethylene used for this process is LDPE, MDPE and HDPE type of polyethylene. The polymerization process of the polymeric material generally follows initiation, chain propagation and finally chain termination process.

Initiation step: this step involves hemolytic fission of the radicals.

$\mathrm{R}-\mathrm{C}-\mathrm{C}-\mathrm{C}-\mathrm{R} \rightarrow \mathrm{R}-\mathrm{C}$. + . C-C - R

Chain propagation step: In this step new free radicals were produced by combining free radicals produced in the above step with the alkenes molecule

$$
\begin{aligned}
& \text { R - C. }+ \text { R - C-C-C - R } \rightarrow \text { R - CH }+ \text { R - C.-C-C - R } \\
& \text { R - C. }-C-C-R \rightarrow R-C .+C=C-R \\
& \text { R - C-C-C. } \rightarrow \text { R - C. }+ \text { C }=\text { C }
\end{aligned}
$$

In this step the chain reaction is terminated by combination or disproportion that is combination or loss of action.

$$
\begin{aligned}
& \text { R - C. }+ \text { R - C. } \rightarrow \text { R - C-C - R } \\
& \text { R - C. +. C-C - R } \rightarrow \text { Dead Polymer }
\end{aligned}
$$

The termination of the step produces unreacted polymer.

The waste polyethylene is difficult to treat due to its complex nature, composition and structural deterioration of the polymeric components and the contamination with various organic, inorganic or biological residues.

In this study the waste polyethylene were degraded by thermal hydropyrolytic process. The degradation process mainly follows the mechanism of chain scissions which is generally caused by increase in temperature and sheer stress in twin-skew extruders and hence decreases the molecular weight. Cross linking or chain branching have opposite effect to chain scission and are caused mainly by low sheer stress and high residence time in a single skew extruders. A concurrence occurs between the molecular enlargement by chain branching and the decrease of molecular weight by chain scission. The thermal degradation of the polymers occurs by breaking $\mathrm{C}-\mathrm{C}$ or $\mathrm{C}-\mathrm{H}$ bonds. Degradation depends on the nature such as polar groups and structure, for example head-to-head or tail-totail weak linkages, double bonds or branching points of the polymeric chain, on the ingredients in the polymer resin and on the type of the external stress.

In free radical mechanisms, the degradation of polymers generally involves the stages of initiation, propagation, chain transfer and termination. Initiation is the slowest reaction stage and generates macroradicals by chain scission or endchain breaking of the macromolecular backbone or by scission of the bonds with the pendant groups. The reactivity of the macroradicals, the $\mathrm{R}-\mathrm{CH}_{2}$. radical has a higher reactivity than the $\mathrm{R}_{2} \mathrm{CH}$. and the mobility of the hydrogen atoms in the backbone, the tertiary hydrogen is more reactive than the secondary and primary one which strongly affects the mechanism of polymer degradation and decomposition.

A variety of products and applications can been observed by the thermal depolymerisation of polymeric materials through hydropyrolytic route. Fuel gases, olefinic gases useful in chemical synthesis, naphtha and middle distillates, oil fractions, long-chain paraffin and olefins, coke, etc. proceeds through a radical mechanism, which generally involve three different decomposition pathways (i) Random scission at any point in the polymer backbone leading to the formation of smaller polymeric fragments as primary products, (ii) End-chain scission, where a small molecule and a long-chain polymeric fragment are formed. The thermal degradation process can be considered as an actual depolymerization or unzipping process. (iii) Abstraction of functional substituent to form small molecules. In this case, the polymer chain may retain its length or the release of the small molecule may be accompanied by cleavage of the polymeric chain.

During the thermal degradation of many polymers other reactions may take place at the same time as the cracking reactions, e.g. isomerization, cyclization, aromatization, recombination of species, etc. Thus, an increase in the degree of branching of the polymeric chains is usually observed as they are reduced in length by thermal decomposition. The thermal decomposition of polymers also involves the formation of volatile species within a highly viscous polymeric matrix. An important factor in the formation of gaseous product is the control of the reaction environment in terms of the components in each phase [4].

Molten polymers are highly viscous fluids with low thermal conductivity; heat transfer limitations may also be present, leading to significant temperature gradients. The steps involved in the hydrothermal de-polymerization of the polyethylene involves the following steps. 
i. Initiation

Random sussion

$-\mathrm{CH} 2-\mathrm{CHX}-\mathrm{CH} 2-\mathrm{CHX}-\rightarrow-\mathrm{CH} 2-\mathrm{CHX}+{ }^{\cdot} \mathrm{CH} 2-\mathrm{CHX}-$

End chain scission

$-\mathrm{CH} 2-\mathrm{CHX}-\mathrm{CH} 2-\mathrm{CH} 2 \mathrm{X} \rightarrow-\mathrm{CH} 2-\mathrm{CHX}+{ }^{-} \mathrm{CH} 2-\mathrm{CH} 2 \mathrm{X}$

ii. Depropogation

$-\mathrm{CH} 2-\mathrm{CHX}-\mathrm{CH} 2-\mathrm{CHX} \rightarrow-\mathrm{CH} 2-\mathrm{CHX}+\mathrm{CH} 2=\mathrm{CHX}$

\section{Hydrogen chain transfer}

Intermolecular

$$
\begin{aligned}
& -\mathrm{CH} 2-\mathrm{CHX}+-\mathrm{CH} 2-\mathrm{CHX}-\mathrm{CH} 2-\mathrm{CHX}-\mathrm{CH} 2- \\
& \rightarrow-\mathrm{CH} 2-\mathrm{CH} 2 \mathrm{X}+-\mathrm{CH} 2-\mathrm{CHX}-\mathrm{CH}=\mathrm{CHX}+{ }^{\circ} \mathrm{CH} 2-
\end{aligned}
$$

$$
\begin{aligned}
& -\mathrm{CH}_{2}-\mathrm{CHX}+-\mathrm{CH} 2-\mathrm{CHX}-\mathrm{CH} 2- \\
& \rightarrow-\mathrm{CH} 2-\mathrm{CH} 2 \mathrm{X}+-\mathrm{CH} 2-\mathrm{CX}-\mathrm{CH} 2-
\end{aligned}
$$

Intramolecular

$$
\begin{aligned}
-\mathrm{CH} 2-\mathrm{CHX}-\mathrm{CH} 2-\mathrm{CHX}-\mathrm{CH} 2 \rightarrow & -\mathrm{CH} 2 \\
& +-\mathrm{CHX}=\mathrm{CH}-\mathrm{CHX}-\mathrm{CH} 3
\end{aligned}
$$

$$
\begin{aligned}
& \beta \text {-Cleavage } \\
& -\mathrm{CHX}-\mathrm{CH} 2-\mathrm{CH}-\mathrm{CH} 2-\rightarrow-\mathrm{CHX}+\mathrm{CH} 2=\mathrm{CH}-\mathrm{CH} 2-
\end{aligned}
$$

Formation of branches
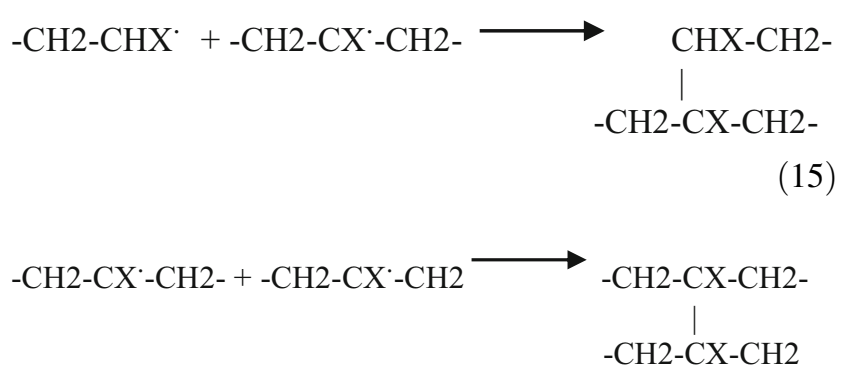

iii. Termination

Bimolecular coupling
$-\mathrm{CHX}-\mathrm{CH} 2+\mathrm{CHX}^{-}-\mathrm{CH} 2-\rightarrow-\mathrm{CHX}-\mathrm{CH} 2-\mathrm{CHX}-\mathrm{CH} 2-$

Disproprotionation

$$
\begin{aligned}
& -\mathrm{CH} 2-\mathrm{CHX}-\mathrm{CH}_{2}+\mathrm{CHX}^{-\mathrm{CH}} 2-\mathrm{CH} 2- \\
& \rightarrow-\mathrm{CH} 2-\mathrm{CHX}-\mathrm{CH} 3+\mathrm{CHX}=\mathrm{CH}-\mathrm{CH} 2-
\end{aligned}
$$

Initiation, involves the succession of first bond in the chain yielding two radicals, which may occur at random or end chain position. De-prorogation resulting in the release of the olefinic monomeric fragments from primary radicals. Hydrogen chain transfer reaction may occur as intermolecular or intra molecular processes. This leads to the formation of olefinic species and polymeric fragments. $\beta$-Cleavage of secondary radicals yields end chain olefinic groups and primary radicals. Branches were observed between two secondary radicals or between secondary and a primary radical. Termination process takes place either in a bimolecular mode, either by coupling of two primary radicals or by disproportion of radicals.

\section{Experimental}

The polyethylene sample were collected and were washed and dried. Then the dried samples were cut into small pieces or converted into pellates. These waste polyethylene pieces or prelates were put into a hopper which is connected with a batch reactor or a vessel. When the reactor or vessel was filled with the waste polyethylene sample, the temperature is raised slowly. At a temperature of about $70{ }^{\circ} \mathrm{C}$ the gasification of the sample starts. With the gradual increase in temperature the sample liquefies and the gasification of the sample increases. The gasified sample was passed through a condenser and was collected in a vessel containing de-mineralized water. The temperature of the water is set at $10{ }^{\circ} \mathrm{C}$. The samples get condensed in water. The liquid samples were observed on the surface of the water. The un-condensed gases escape above the surface of the water. These gases were again transferred to another vessel (secondary vessel) containing water temperature maintained at below $10{ }^{\circ} \mathrm{C}$. The gases which do not get condensed in the chilled water in the secondary vessel were collected for further analysis. The process diagram of the hydropyrolytic depolymerization of thre polyethylene mix is shown in the Fig. 2. The gases recovered from the secondary vessel (water bath 2) were collected. The gas chromatographic analysis of the gases was then carried out. The temperature yield graph is shown below in Fig. 1.

The temperature yield graph shows the variation of the yield of the gases at various temperature range. At certain

Bimolecular coupling 


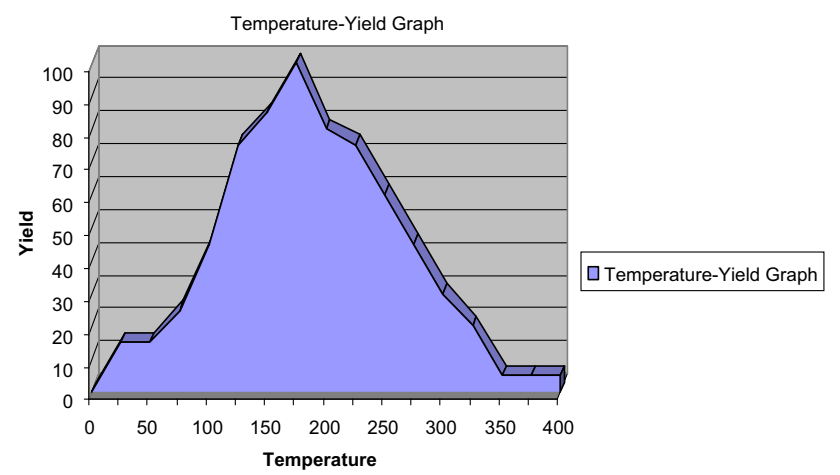

Fig. 1 Temperature-yield graph of the gaseous product obtained by the hydropyrolytic depolymerisation of waste polyethylene elevated temperature maximum amount of gases were recovered. The gas chromatography analysis of the gaseous product was carried out using Thermo Fischer GC. The column used for the purpose was Porapak Q and Molecular Sheve columns. The capillary column used for the purpose of FID analysis of gases is Plot Alumina column. Helium and argon were used as a carrier gas. The gases were analyzed using duel channel TCD and FID detectors. The temperature of the column are programmed in the range of 45-180 ${ }^{\circ} \mathrm{C}$. The Split type of column with ramp temperature of $5^{\circ} \mathrm{C}$ per minute was set $[5,6,7]$. The chromatographic peak with there retention time for the recovered gases from the hydropyrolytic depolymerisation of waste polyethylene into gaseous product are shown in Figs. 3, 4

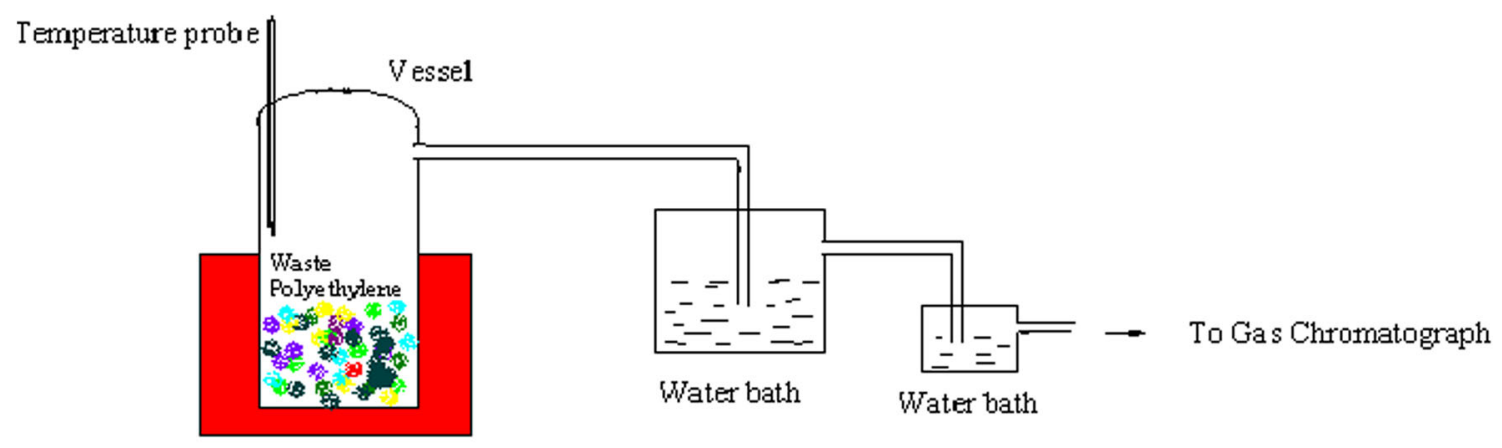

Heating source

Fig. 2 Diagram showing the process of the hydropyrolytic depolymerization of LDPE, MDPE and HDPE polyethylene mix

polyethylene mix.

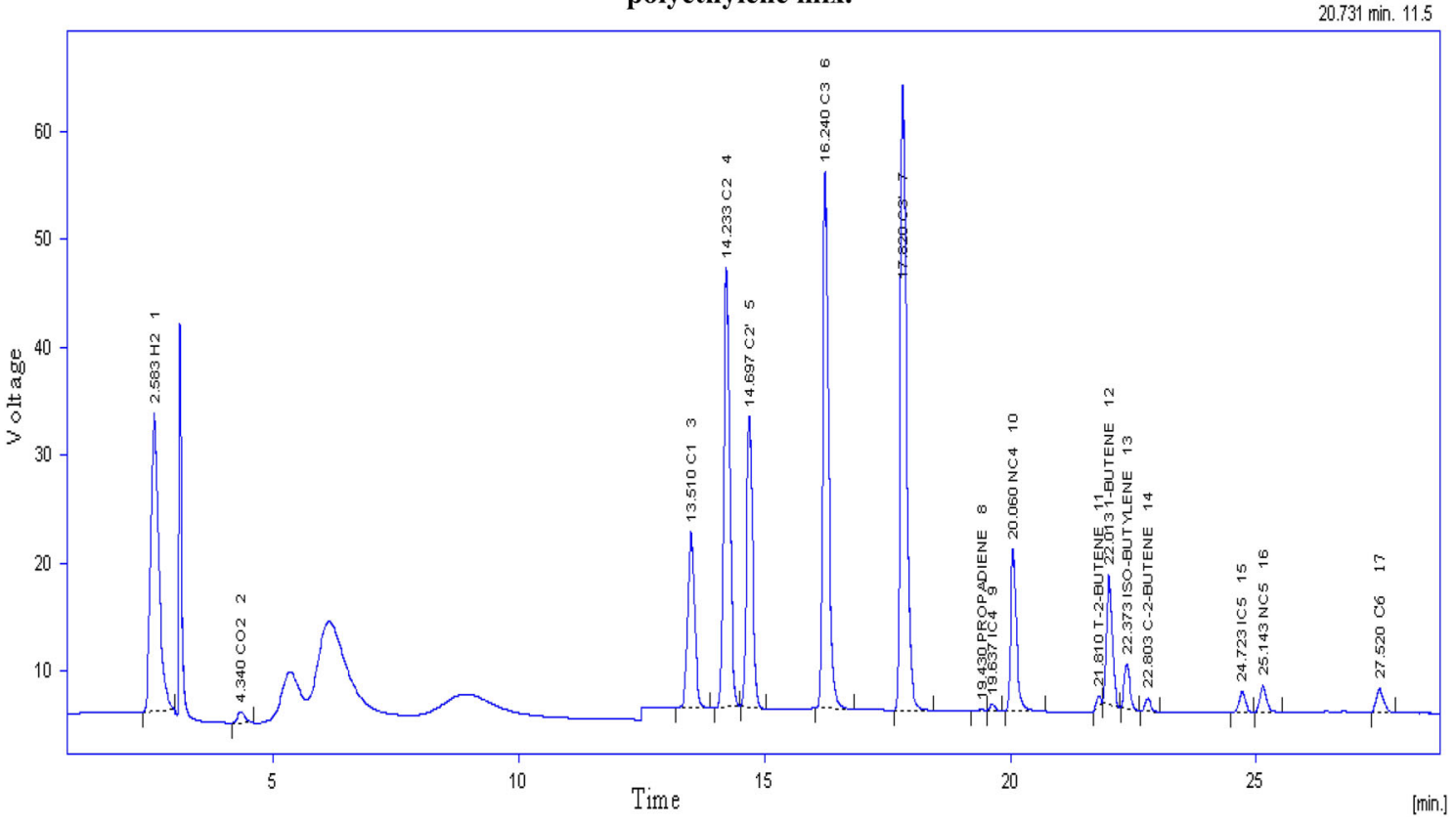

Fig. 3 Gas chromatography analysis of the recovered gases from hydropyrolysis of waste polyethylene 


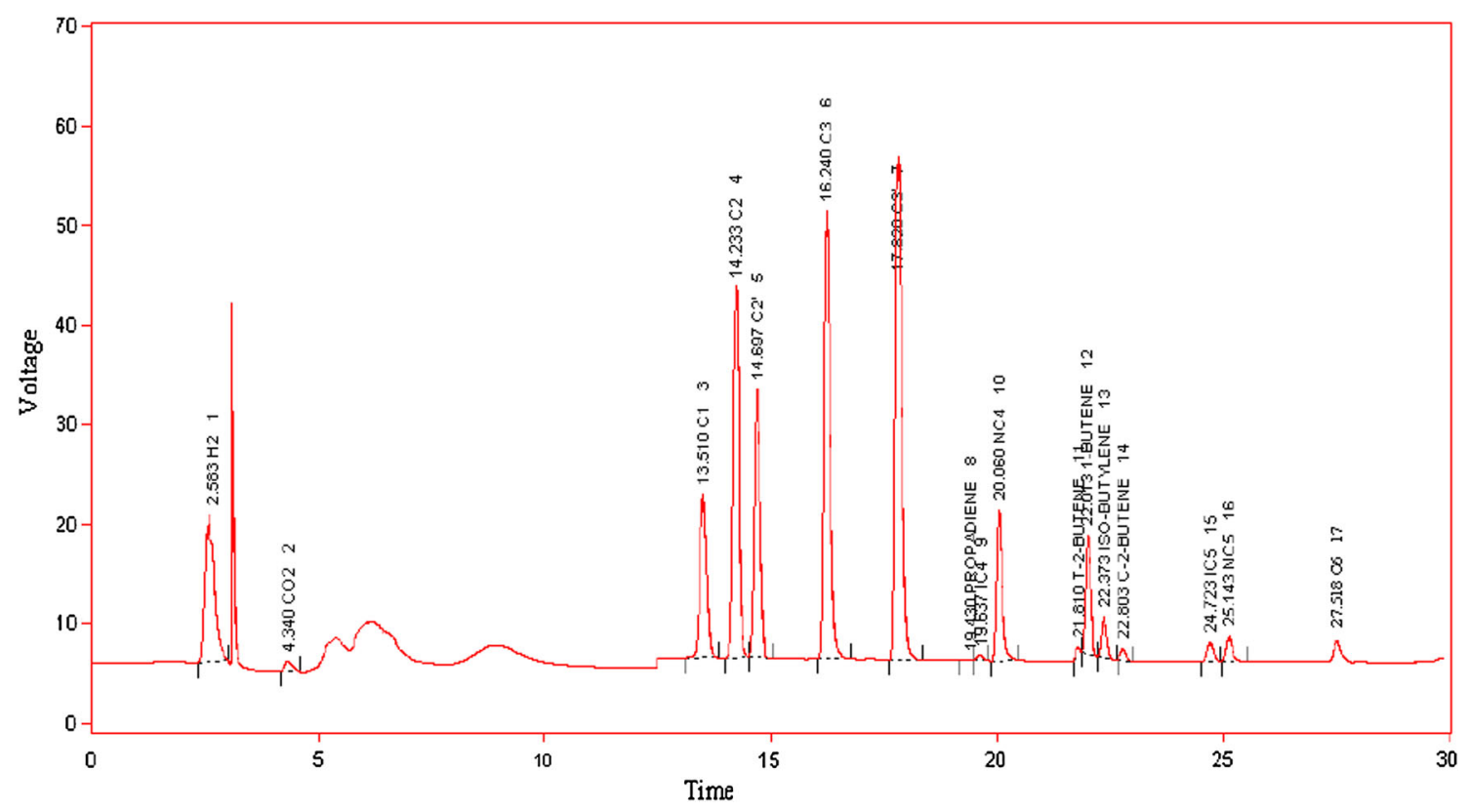

Fig. 4 Gas chromatography analysis of the recovered gases from hydropyrolysis of waste polyethylene

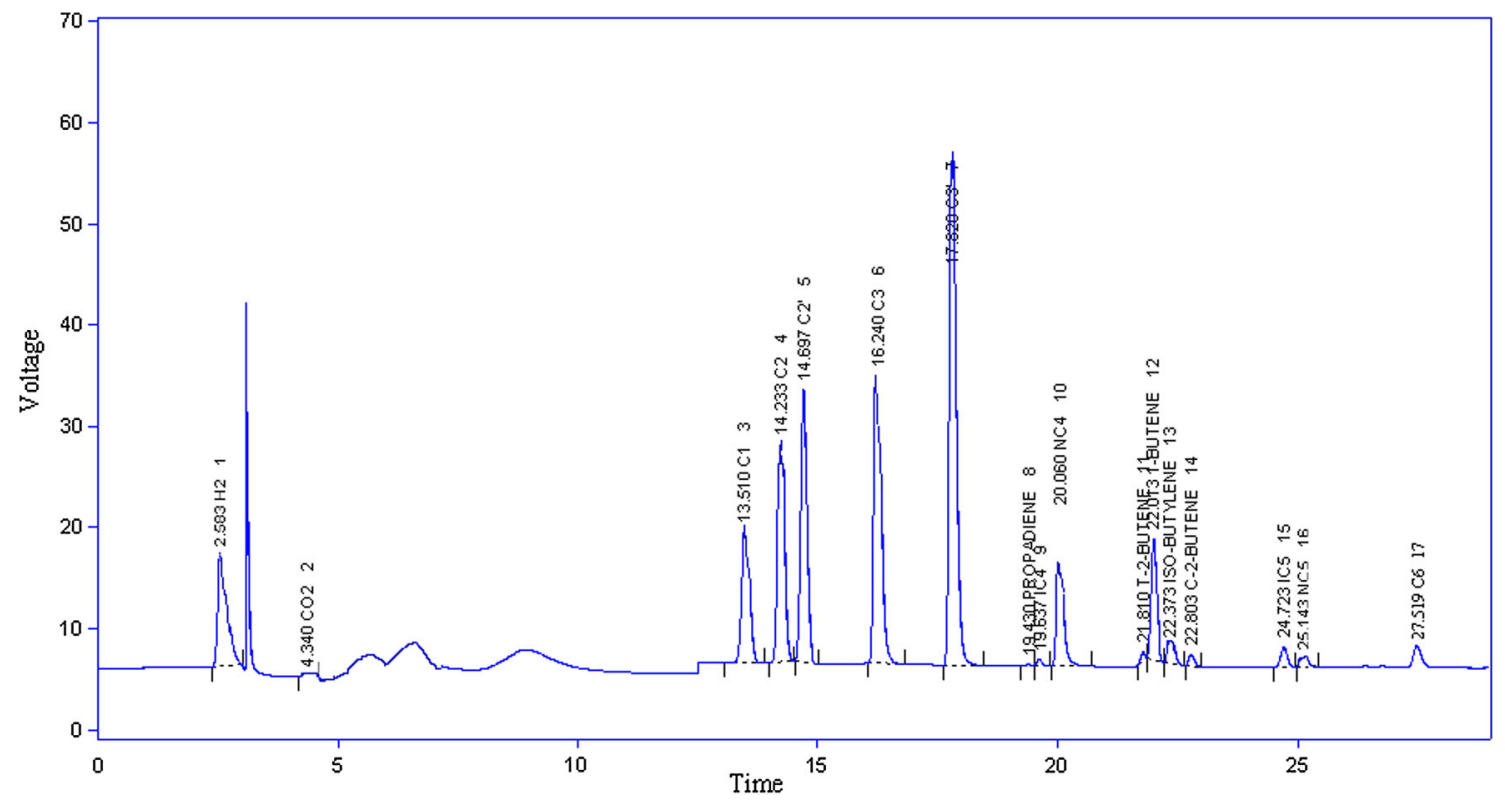

Fig. 5 Gas chromatography analysis of the recovered gases from hydropyrolysis of waste polyethylene

and 5. A number of chromatographic experiments were conducted and the different components of the gaseous products were collected.

The volatile components were analyzed and compared with the known standards. The concentration of the gaseous components was identified and there concentration on v/v basis was observed. The Tables 1, 2 and 3 shows the concentration of the gaseous product recovered by the gas chromatographic analysis. A number of experiments were carried out and the different gaseous samples were collected with different sample (LDPE, MDPE and HDPE) mix.

The gases produced by hydropyrolysis of the polyethylene materials produces more than $80 \%$ of the hydrocarbon gaseous products and about 11.3, 7.7 and $7.3 \%$ of the Hydrogen respectively. The Hydrogen is produced during the cracking of the long chain polymeric chain. This hydrogen plays a crucial part in the formation 
Table 1 Components observed by gas chromatography analysis of the recovered gases from hydropyrolytic depolymerisation of waste polyethylene mix as per Fig. 3

\begin{tabular}{lll}
\hline Hydrocarbon types & Components & Concentration V/V \% \\
\hline & H2 1 & 11.3 \\
$\mathrm{C} 2$ & Methane & 15.3 \\
& Ethane & 15.7 \\
$\mathrm{C} 3$ & Ethylene & 10.7 \\
& Propane & 13.7 \\
$\mathrm{C} 4$ & Propylene & 16.2 \\
& Propadiene & 0.1 \\
& Iso-Butane & 0.1 \\
& N-Butane & 3.4 \\
& Trans-2 Butene & 0.2 \\
& 1-Butene & 3.2 \\
& Iso-butylene & 0.8 \\
C5 & Cis-2-Butene & 0.3 \\
& Iso-pentane & 0.2 \\
C6 & N-pentane & 0.5 \\
& C6 components & 0.5 \\
& CO2 & 7.8 \\
\hline
\end{tabular}

Table 2 Components observed by gas chromatography analysis of the recovered gases from hydropyrolytic depolymerisation of waste polyethylene mix as per Fig. 4

\begin{tabular}{llr}
\hline Hydrocarbon types & Components & Concentration V/V \% \\
\hline & H2 & 7.7 \\
C2 & Methane & 13.2 \\
& Ethane & 15.5 \\
C3 & Ethylene & 13.9 \\
& Propane & 15.8 \\
C4 & Propylene & 17.5 \\
& Propadiene & 0.1 \\
& Iso-Butane & 0.1 \\
& N-Butane & 3.4 \\
& Trans-2 Butene & 0.3 \\
& 1- Butene & 3.7 \\
& Iso-butylene & 0.8 \\
C5 & Cis-2-Butene & 0.3 \\
& Iso-pentane & 0.3 \\
C6 & N-pentane & 0.6 \\
& C6 components & 1.1 \\
\hline
\end{tabular}

of the gaseous and liquid hydrocarbon products. These hydrogen atoms get attached with the short chain polymers and cracked polymer components producing short chain stable components. The remaining hydrogen remains unreacted and releases along with the hydrocarbon gases.
Table 3 Components observed by Gas chromatography analysis of the recovered gases from hydropyrolytic depolymerisation of waste polyethylene mix as per Fig. 5

\begin{tabular}{llr}
\hline Hydrocarbon types & Components & Concentration V/V \% \\
\hline & H2 & 7.2 \\
C2 & Methane & 15.4 \\
& Ethane & 12.7 \\
C3 & Ethylene & 16.8 \\
& Propane & 16.7 \\
C4 & Propylene & 18.2 \\
& Propadiene & 0.1 \\
& Iso-Butane & 0.1 \\
& N-Butane & 3.8 \\
& Trans-2 Butene & 0.3 \\
& 1- Butene & 3.6 \\
& Iso-butylene & 0.7 \\
C5 & Cis-2-Butene & 0.4 \\
& Iso-pentane & 0.3 \\
C6 & N-pentane & 0.6 \\
& C6 components & 1.2 \\
& CO2 & 1.7 \\
\hline
\end{tabular}

This hydrogen can be extracted from the hydrocarbon fuel to produce fuels and to carry out other chemical reactions. A small amount of $\mathrm{CO}_{2}$ is also observed in the gas composition. Some traces of $\mathrm{CO}$ is also observed in the process. The formation of the traces of the $\mathrm{CO}$ and the $\mathrm{CO} 2$ is due to the presence of the local content of the oxygen. The rate of carbon converted into $\mathrm{CO}$ and $\mathrm{CO} 2$ increases when the local oxygen content increases [10]. Along with the $\mathrm{C} 1-\mathrm{C} 4$ hydrocarbons some C5 and C6 component peaks are also observed, which can be extracted and condensed separately at lower temperature to produce C5 and C6 liquid components.

In contrast to the thermal polyethylene cracking products with straight-chain hydrocarbon structure, the formation of compounds with branched high prevailing unsaturated hydrocarbons structure is characteristic for polypropylene. It corresponds to the analogous free radical degradation mechanisms and different molecular structure of both polyalkenes. Due to the polypropylene branched structure the variety of products is more complex than from polyethylene degradation, and the stereoisomers are formed [8].

It can be deduced that the primary pyrolysis of polyethylene takes place through a free radical transfer that leads to low yield of gases. Nevertheless the more gases are obtained from the secondary pyrolysis of waxes at gas phase can be interpreted as a consequence of the propagation reaction [9].

The gas chromatographic analysis of the above gaseous products as shown in Figs. 3, 4 and 5 were compared with 


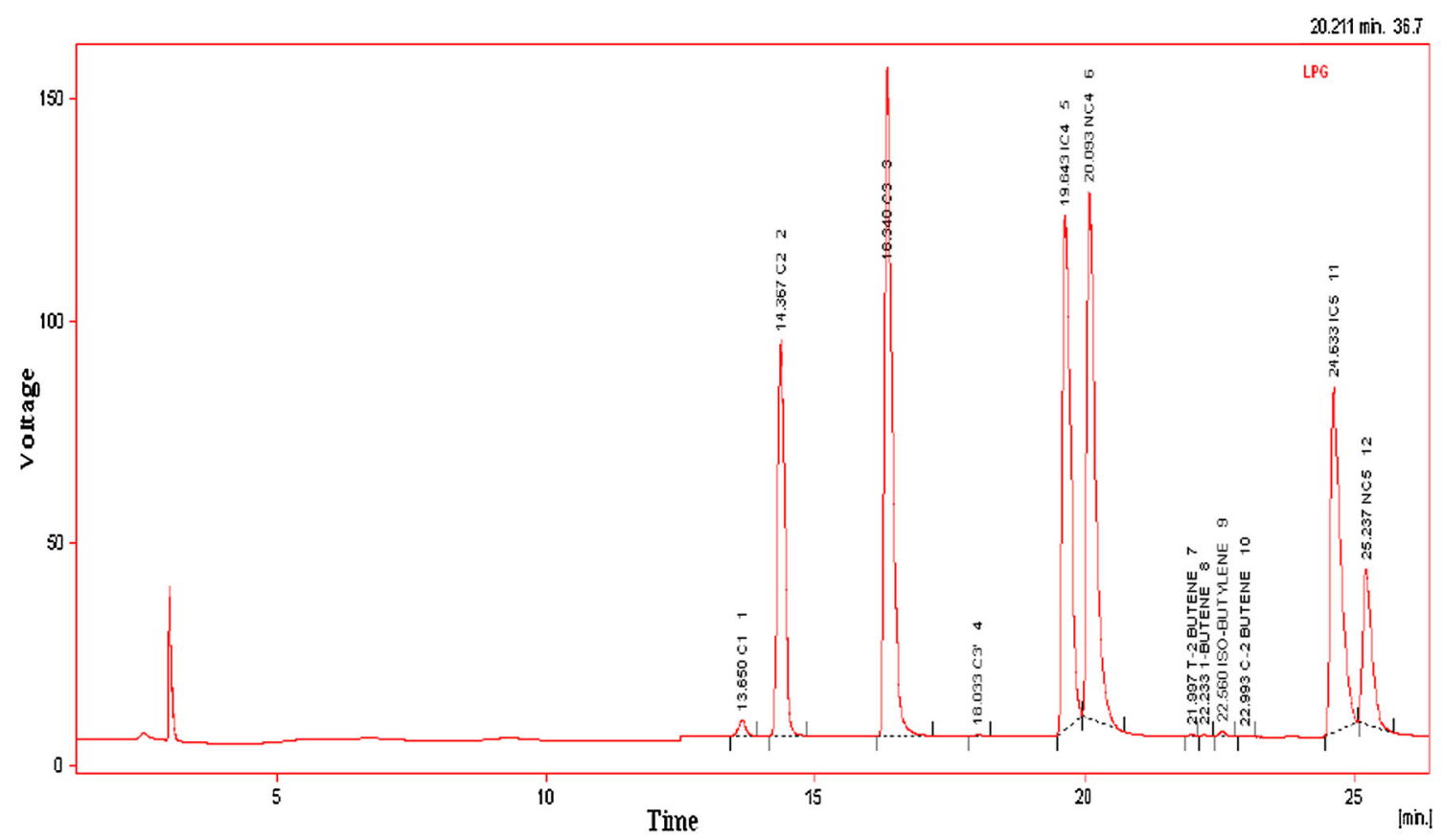

Fig. 6 Gas chromatography analysis of a LPG sample (partially processed)

Table 4 Components observed by gas chromatography analysis of lpg gas (partially processed)

\begin{tabular}{llc}
\hline Hydrocarbon types & Components & Concentration V/V \% \\
\hline C1 & Methane & 0.5 \\
C2 & Ethane & 1.16 \\
& Ethylene & 1.52 \\
C3 & Propane & 4.68 \\
& Propylene & 12.63 \\
C4 & Propadiene & 1.59 \\
& Iso-Butane & 11.19 \\
& N-Butane & 40.39 \\
& Trans-2 Butene & 6.78 \\
& 1- Butene & 1.41 \\
& Iso-butylene & 7.21 \\
C5 & Cis-2-Butene & 6.93 \\
& Iso-pentane & 1.21 \\
\hline
\end{tabular}

the Liquefied Petroleum Gas components. The chromatography study of one of partially processed Liquefied Petroleum Gas is shown in Fig. 6. The Liquefied petroleum gases mainly consist of components of $\mathrm{C} 3$ and $\mathrm{C} 4$, with traces of $\mathrm{C} 1, \mathrm{C} 2$ and $\mathrm{C} 5$ components.

The component analysis of the typical Liquefied Petroleum Gas received from an Oil refinery is given in the above Table 2. The component analysis of the gases recovered by the hydropyrolytic depolymerisation of
LDPE, MDPE and HDPE type of waste polyethylene as described in Figs. 3, 4 and 5; Tables 1, 2 and 3 is compared with the LPG components as described in Fig. 6; Table 4. It was observed that the components of the gases recovered in Table 4. containing mainly Hydrogen, C1, C2, C3, C4, and $\mathrm{C} 5$ components.

The C3, C4 and C5 components are mainly present in the recovered gases in Tables 1, 2 and 3 which is in between 38 and $45 \%$. The percentage of the C3 components are found is more in percentage than that of $\mathrm{C} 4$ components. The $\mathrm{C} 3$ components were observed to be more than $29 \%$ of the total volume of the recovered gases. This reveals that, the above recovered gases by depolymerisation of waste polyethylene mix have very excellent fuel property. Propane, Propylene (C3 components) and C4 components can be recovered from the above recovered gases as domestic fuel (as liquefied petroleum gas) and industrial purposes.

\section{Conclusion}

The process for the extraction of gaseous hydrocarbon products from the hydropyrolytic depolymerisation of waste LDPE, MDPE and HDPE mix type of polyethylene is described in this paper. The experimentation of the extraction of the gaseous hydrocarbon fuel from waste polyethylene is carried out on a lab scale basis. The temperature versus yield graph is also described in this paper, which depicts the increase in the yield of the gaseous fuel

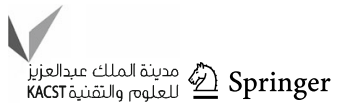


with temperature is obtained up to certain temperature, but at certain higher temperature the yield of the gaseous fuel decreases. The component analysis of the products with Gas Chromatographs is carried out and the gaseous hydrocarbon gaseous products were compared with the conventional liquefied petroleum gas components. The paper produces some scope for the possibilities of production of $\mathrm{C} 3$ and $\mathrm{C} 4$ components as useful domestic and industrial fuel. The chromatographic study, reveal that more than $29 \%$ of the total volume of the gas component is C3. This is also evident for the production of higher calorific value products from the hydropyrolytic process of depolymerisation of waste polyethylene. The stripping of the $\mathrm{C} 1$ and $\mathrm{C} 2$ components from the above gaseous fuel can be used as a fuel gas in furnaces. The paper also provides information regarding the percentage of the gaseous fuel extracted from waste polyethylene. The scope for generating a source for an alternative fuel is well reveled in this paper.

Acknowledgments The author is indebted to Mr. K. Kharkongar, DGM, Technical Services, Barauni Refinery, Indian Oil Corporation Limited, Mr. Kartik Paswan, Quality Control Manager, Mr. A. S. Sarkar, Ex Deputy Manager Quality Control, Dr. Kajal Ambuj, Senior Quality Control Officer and Mr. Bhag Singh, Quality Control Officer QC Lab Barauni Refinery, Indian Oil Corporation Limited for providing guidance and technical assistance for completing this paper.

Open Access This article is distributed under the terms of the Creative Commons Attribution 4.0 International License (http:// creativecommons.org/licenses/by/4.0/), which permits unrestricted use, distribution, and reproduction in any medium, provided you give appropriate credit to the original author(s) and the source, provide a link to the Creative Commons license, and indicate if changes were made.

\section{References}

1. 4R Sustainability Inc (2001) Portland conversion molecular ratio technology: a compliment to recycling technology. April 2001, 3, 6

2. Thermofuel (2013) Pyrolysis of waste plastic to produce Liquid Hydroocarbons. Dr. P.V. Thorata, Miss. Sandhya Warulkara, Miss. Harshal Sathonea advances in Polymer Science and Technology: An International Journal, 01 February 2013, 1, 1

3. Kumar S, Singh RK (2011) Recovery of hydrocarbon liquid from waste high density polyethylene by thermal pyrolysis. Braz J Chem Eng 28(04):659-667. October-December, 2011, 660, 1

4. Kodera Y, Ishihara Y (2005) Novel process for recycling waste plastics to fuel gas using a moving-bed reactor. Energ Fuel 20(1): 1,5

5. ASTM D-1945-07. Standard test method for analysis of natural gas by gas chromatography, pp 1-17

6. ASTM D-1946-90. Standard practice for analysis of reformed gas by gas chromatography, pp 1-6

7. ASTM D-2597-94. Standard test method for analysis of demethanied hydrocarbon liquid mixtures containing nitrogen and carbon dioxide by gas chromatography, pp 1-10

8. Sojáka L, Kubineca R, Jurdákováa H, Hájekováb E, Bajusb M (2006) GC-MS of polyethylene and polypropylene thermal cracking products. Petroleum Coal 48(1):1-14, 2006, 2, 7

9. Ammar S, Abbas, Sawsan DA, Iraqi S (2008) Pyrolysis of highdensity polyethylene for the production of fuel-like liquid hydrocarbon. J Chem Petroleum Eng 9(1):25, 6

10. Ouiminga SK, Rogaume T, Daho T, Richard F, Koulidiati J (2012) Thermal degradation of polyethylene bags and millet stalks: influence of the temperature and the local concentration of oxygen on the conversion rate of carbon. Adv Chem Eng Sci 161, 2. doi:10.4236/aces.2012.21019 